بررسى اثر دبى قطرهجكان و نوع بستر كشت بر الكوى توزيع رطوبت در بسترهاى كثت بدون خاك

سيده افسانه احمدى فروشانى'، مهدى قبادىنيا'، رحيم برزگرّ و روحاله فتاحى نافجى'

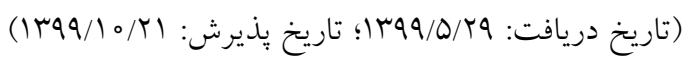

جكيده

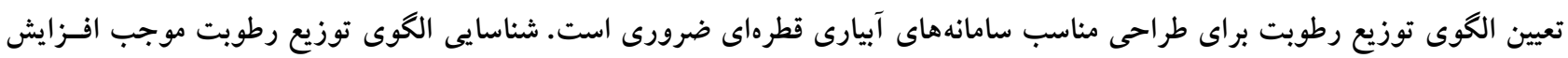

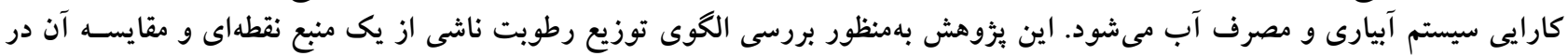

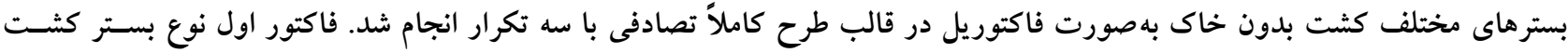

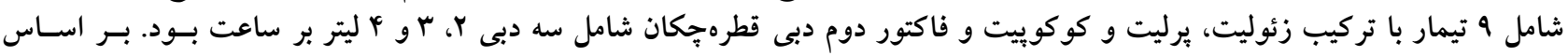

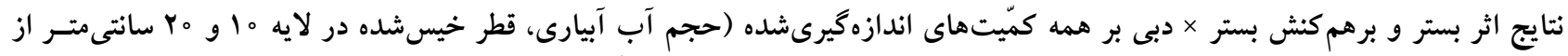

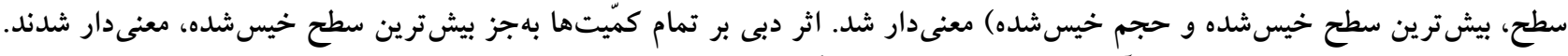

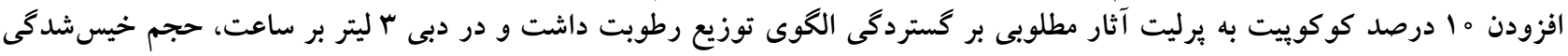

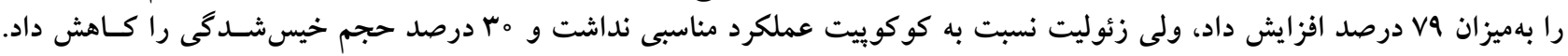

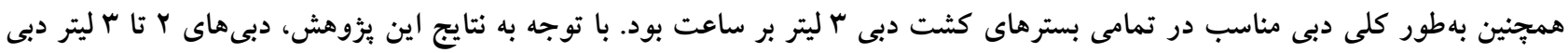

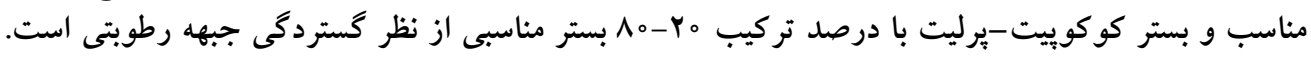

وازمهاى كليدى: آبيارى قطرهاى، الكوى توزيع رطوبت، بستر كشت بدون خاك، زئوليت، كوكوييت

خاكزى به علت ضدعفونى بودن اكثر بسترها، صـرفهجـويى در

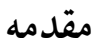

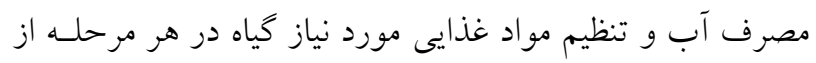
سيستمهاى كشت بدون خاك يكى از روشهاى نـوين و مــدرن

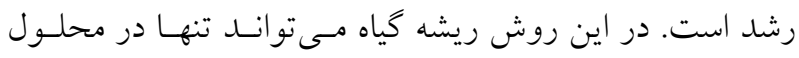

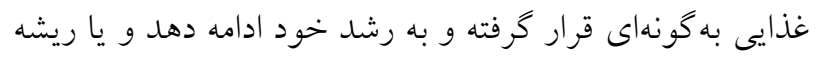

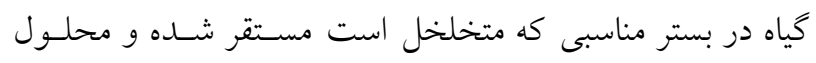

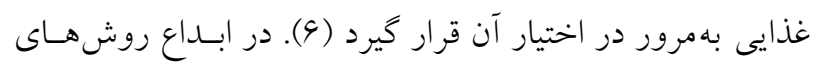

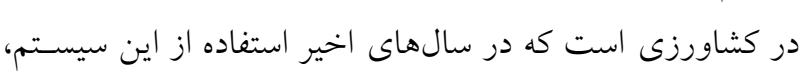

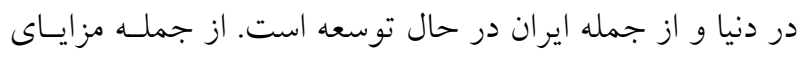

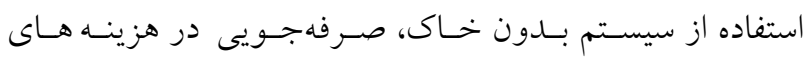

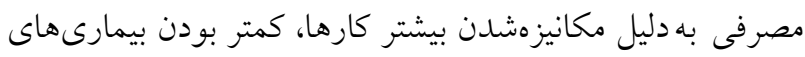

\footnotetext{
1. گروه مهندسى آب، دانشخاه شهركرد

r. كروه باغبانى، دانشخاه شهر كرد
}

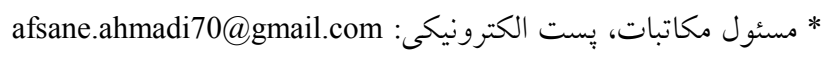




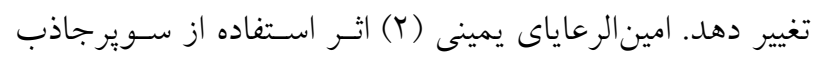

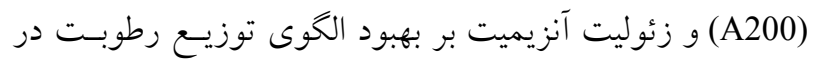

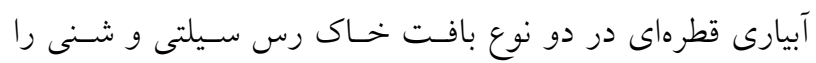

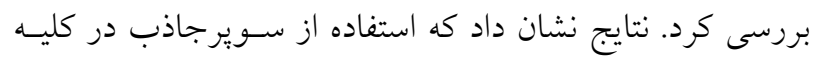

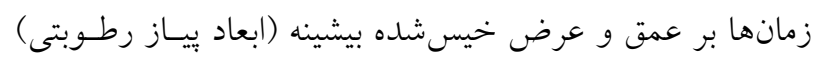

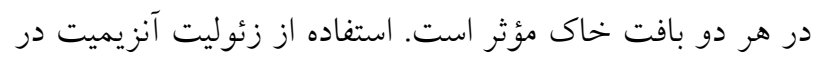

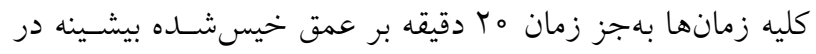

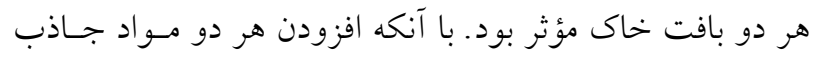

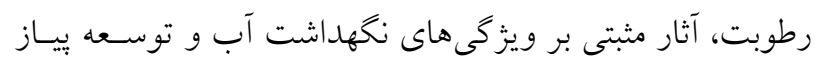

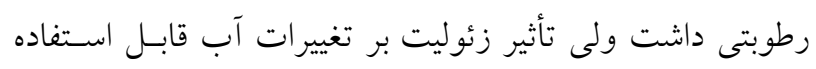

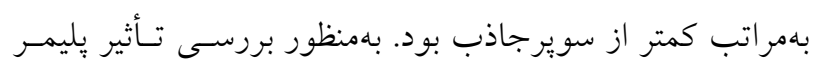

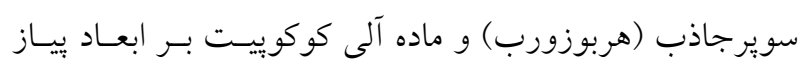

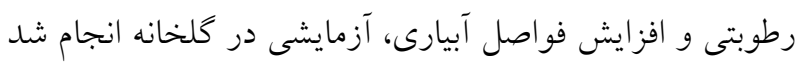

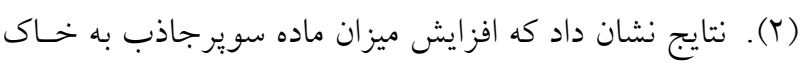
باعث افزايش عرض و كاهش عمق خيس شدكى شد، اما كاربرد

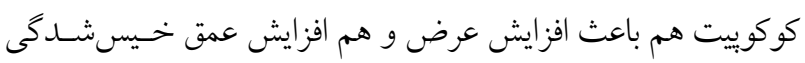

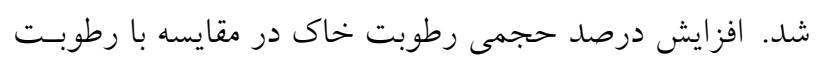

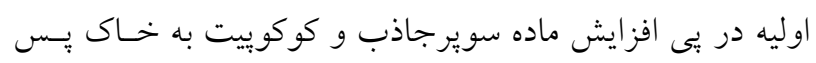

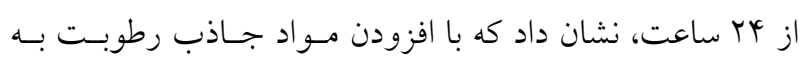

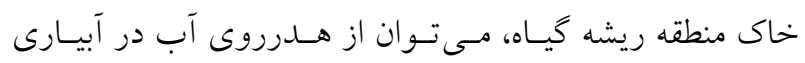

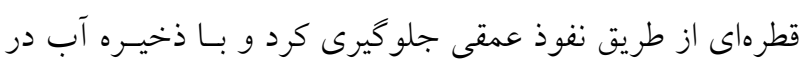

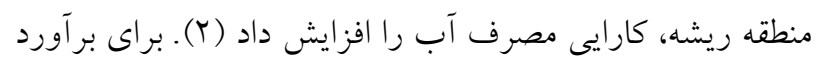

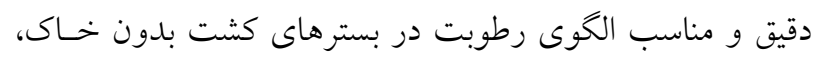

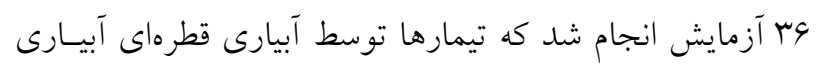

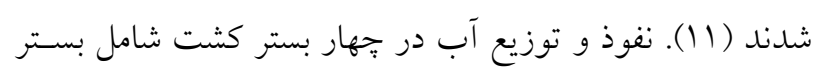

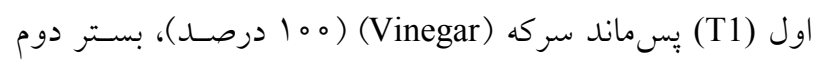

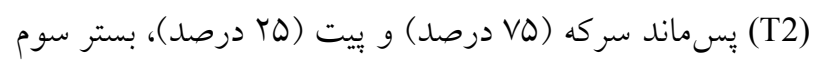

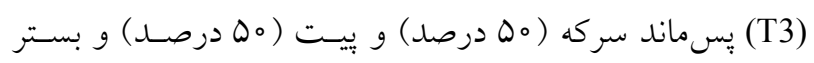

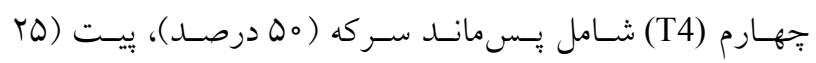

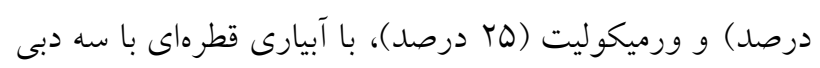

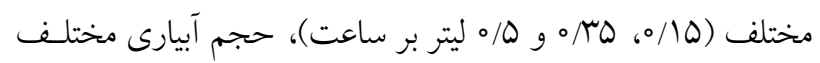

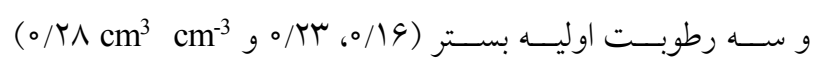

نوين آبيارى آنجه كه مدنظر است، اين است كـه آب بـه انـدازه

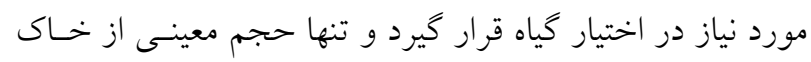

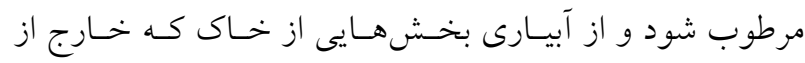

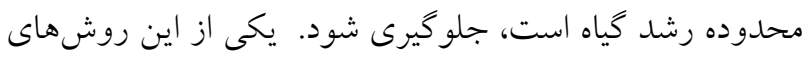

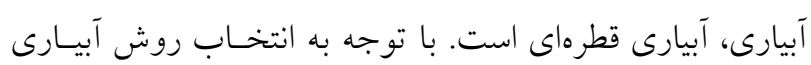

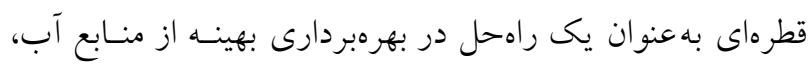

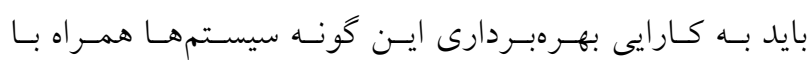

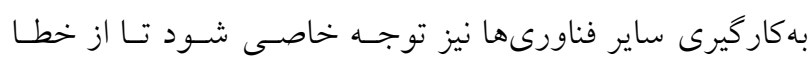
مصون و از تكرار اشتباه برهيز شود (1).

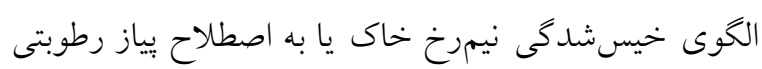

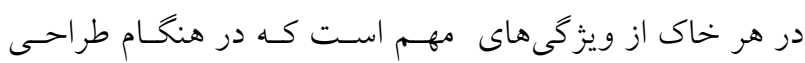

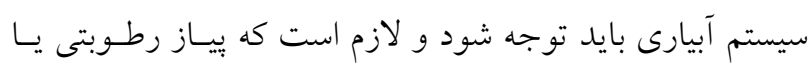
حجم خاك خيسشده براى هر نوع خـاك و بسـترى كـه قـرار

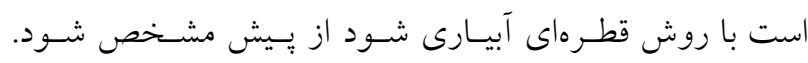

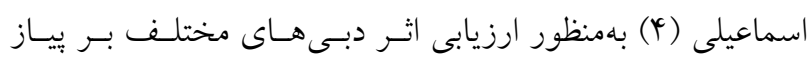
رطوبتى سيستم آبيارى قطرهاى-نوارى (T-Tape) در زمينهاى

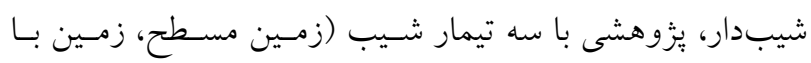

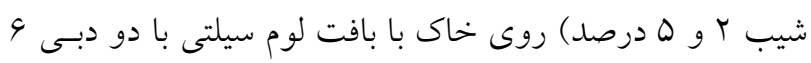

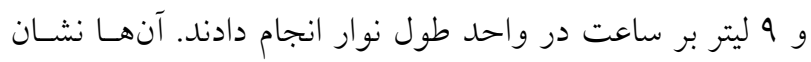

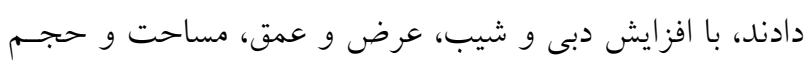

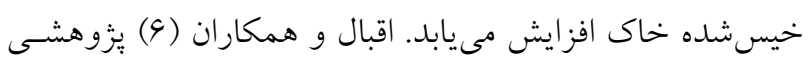

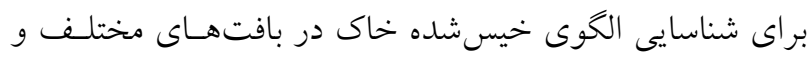

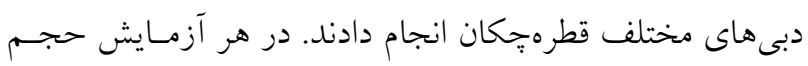

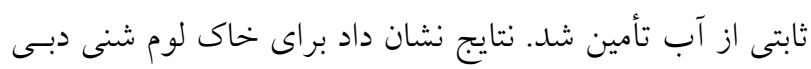

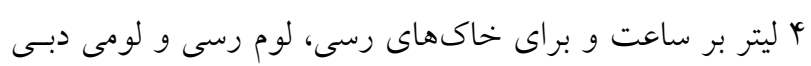

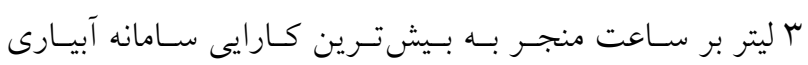

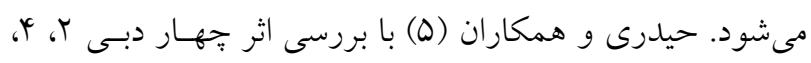

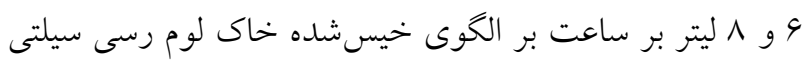

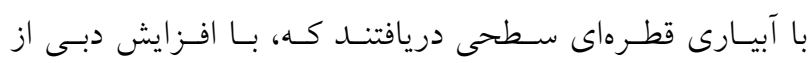

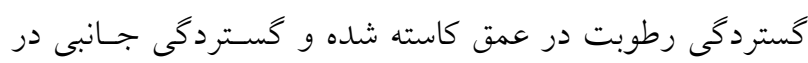
سطح افز ايش مى يابد.

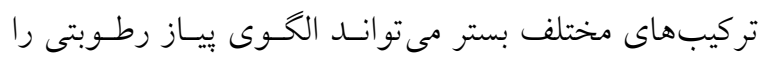




$$
\text { جدول ا. تركيب بسترهاى كشت مورد بررسى. }
$$

Table 1. The composition of the growth media examined.

\begin{tabular}{|c|c|c|}
\hline 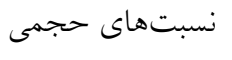 & 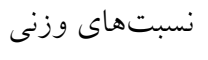 & بستر \\
\hline Volumetric ratio & Weight ratio & Growth media \\
\hline $100 \%$ & $100 \%$ & يرليت (perlite) \\
\hline $10 \%-90 \%$ & $5 \%-95 \%$ & يرليت-كوكوييت (cocopeat-perlite) \\
\hline $20 \%-80 \%$ & $10 \%-90 \%$ & يرليت- كو كوييت (cocopeat-perlite) \\
\hline $30 \%-70 \%$ & $15 \%-85 \%$ & يرليت-كوكوييت (cocopeat-perlite) \\
\hline $40 \%-60 \%$ & $20 \%-80 \%$ & يرليت - كو كوييت (cocopeat-perlite) \\
\hline $5 \%-95 \%$ & $2.5 \% 97.5 \%$ & يرليت-كوكوييت(cocopeat-perlite) \\
\hline $10 \%-90 \%$ & $5 \%-95 \%$ & يرليت-زئوليت (zeolite-perlite) \\
\hline $15 \%-85 \%$ & $7.5 \%-92.5 \%$ & يرليت-زئوليت (zeolite-perlite) \\
\hline $20 \%-80 \%$ & $10 \%-90 \%$ & يرليت-زئوليت (zeolite-perlite) \\
\hline
\end{tabular}

انجام شــــ آزمـايش بـهـــورت فاكتوريـل در قالـب طـرح كـاملاً تصادفى با سه تكرار انجام شد. فـاكتور اول بسـتر كشـت شـامل 9

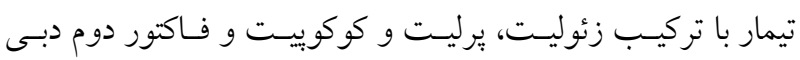

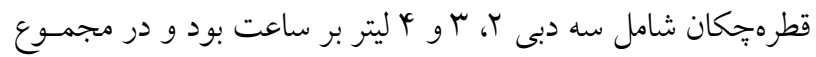

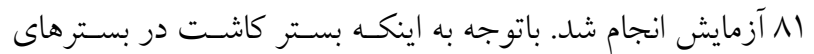

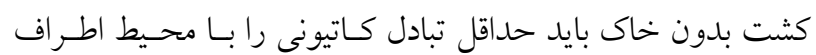

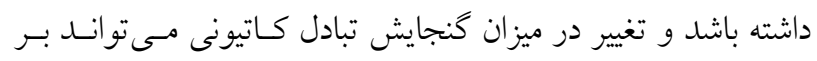

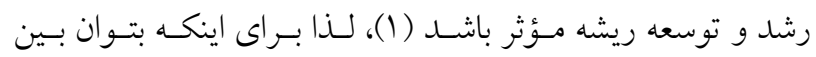
بسترهاى مختلف كشت شرايط تقريباً يكسـان ايجـاد نمـود، مقــدار

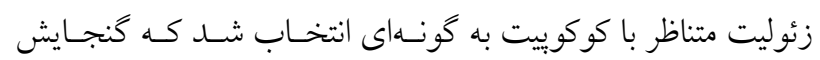

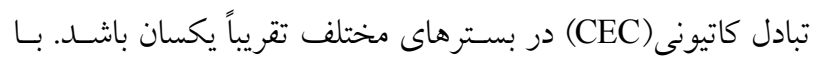

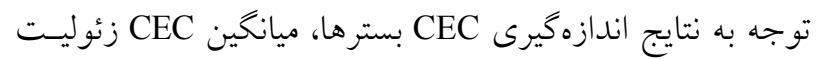

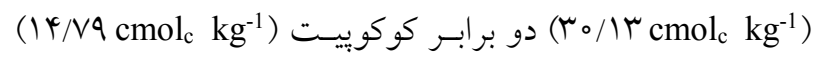

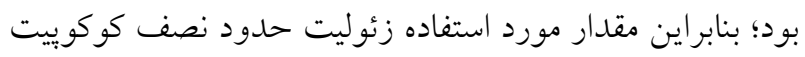
درنظر كرفته شد. تركيب بستر بر اساس نسـبت وزنسى مورد انتخـاب شد و بسترهاى كشت با تركيب زئوليت، برليت و كوكوييت بـهـ شرح جدول (1) ساخته شدند. جدول (Y) تيمارهاى مختلف طرح، علامتها و بارامترهاى

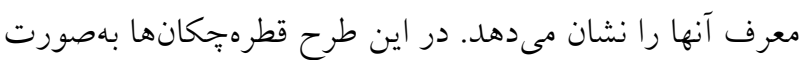
كاملاً افقى روى سطح خاى نصب ران شدند.
بررسى شد و يكى مــل تجربسى بـراى بــيشبينى الحـوى كامـل رطوبت بستر در زمـانهـاى مختلـف كـاربرد بـراى خهـار بسـتر

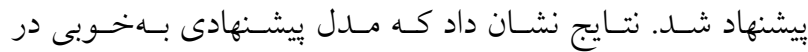

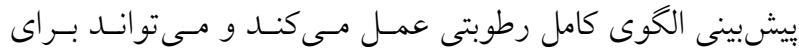
راهاندازى و مديريت سيستم آبيارى استفاده شود (11).

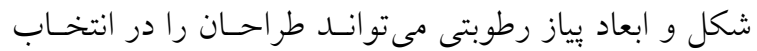

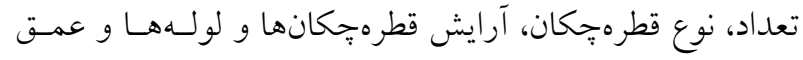
كاشت راهنمايى كند. همجنين مقدار محصول توليدى از مزرعه

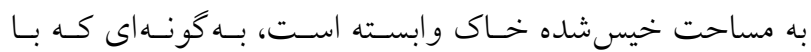
بهينه سازى آن مقدار محصـول توليـــى نيـز افـزايش مسى يابــ؛

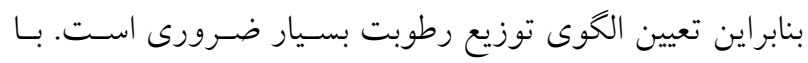

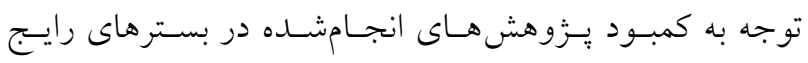

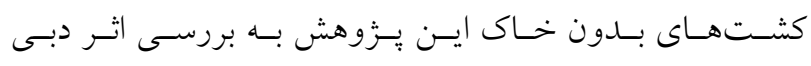

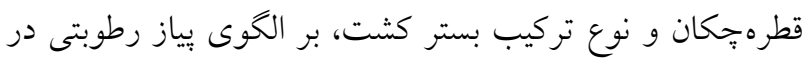
بسترهاى كشت بدون خاك مى يردازد.

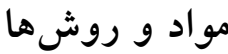

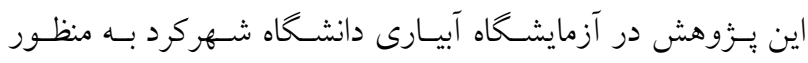

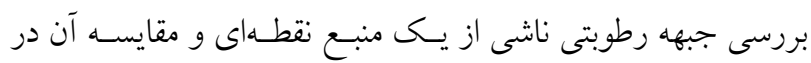

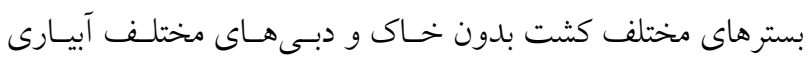


جدول r. نام كذارى تيمارهاى آزمايشى.

Table 2. Nomination of experimental treatments.

\begin{tabular}{|c|c|c|c|c|}
\hline 4 & 3 & 2 & & دبى قطرهجِكان (ليتر بر ساعت) \\
\hline Q4 & Q3 & Q2 & شاخص معرف & بستر كشت \\
\hline P100Q4 & P100Q3 & P100Q2 & P100 & يرليت (perlite) \\
\hline P95C05Q4 & P95C05Q3 & P95C05Q2 & $\mathrm{P} 95 \mathrm{C} 05$ & يرليت -كو كوييت (cocopeat-perlite) \\
\hline P90C10Q4 & P90C10Q3 & P90C10Q2 & P90C10 & يرليت -كوكوييت (cocopeat-perlite) \\
\hline $\mathrm{P} 85 \mathrm{C} 15 \mathrm{Q} 4$ & P85C15Q3 & $\mathrm{P} 85 \mathrm{C} 15 \mathrm{Q} 2$ & $\mathrm{P} 85 \mathrm{C} 15$ & يرليت -كوكوييت (cocopeat-perlite) \\
\hline P80C20Q4 & P80C20Q3 & P80C20Q2 & $\mathrm{P} 80 \mathrm{C} 20$ & يرليت -كوكوييت (cocopeat-perlite) \\
\hline P97.5Z2.5Q4 & P97.5Z2.5Q3 & P97.5Z2.5Q2 & P97.5Z2.5 & يرليت-زئوليت (zeolite-perlite) \\
\hline P95Z05Q4 & P95Z05Q3 & P95Z05Q2 & P95Z05 & يرليت-زئوليت (zeolite-perlite) \\
\hline P92.5Z7.5Q4 & P92.5Z7.5Q3 & P92.5Z7.5Q2 & P92.5Z7.5 & يرليت-زئوليت (zeolite-perlite) \\
\hline P90Z10Q4 & P90Z10Q3 & P90Z10Q2 & P90Z10 & بيرليت-زئوليت (zeolite-perlite) \\
\hline
\end{tabular}

P, Z, C and Q indicate perlite, zeolite, cocopeat and discharge, respectively, and the numerals indicate the weight percentages of the materials in the substrate.

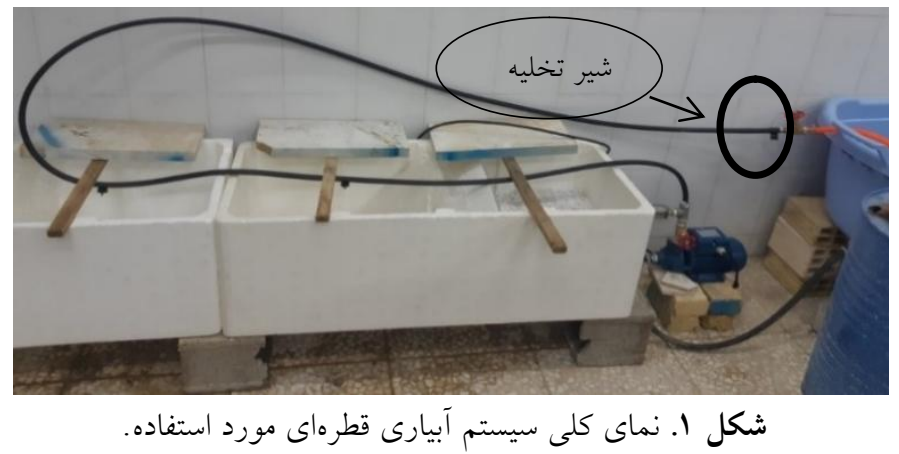

Fig. 1. An overview of the used drip irrigation system.

و فشار متصل شد كه با باز و بسته كردن شـير فلكـهـ و تغييـر دبسى،

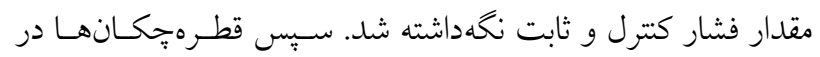
مسير قرار داشتند و انتهاى لوله دوباره به مخـزن بـر مسى گثـت. در انتهاى لوله نيز يك شير فلكه انتهـايى بـراى تخليـه آب لولـهـــا در صورت نياز و تنظيم نهايى دبى و فشار قرار داده شــده بـود. شـكل (1) شمايى كلى از سيستم آبيارى را نشان مىدهد.

با قرار دادن يك خروجى آب در مركز هـر بسـتر و روشـن كردن بمبٍ آزمايش شروع شد و آبيارى تا زمـانى ادامـه داشـت
براى اجراى آبيارى قطرهاى و تعيين بياز رطـوبتى در خـاك از يـك مدل فيزيكى از جنس يونوليت (جعبههاى متداول مورد استفاده در

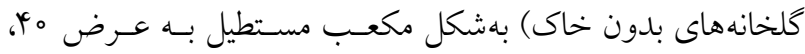

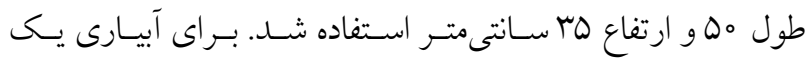

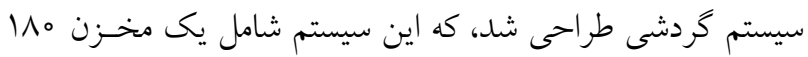
ليترى، يك يمبٍ آب، فشارسنج، قطرهجِكـانهـا و شـيرهاى تنظـيم جريان بود. مخزن بهوسيله يك لوله 19 ميلى مترى بـه يمـِّ وصـل شد و خروجى بِمٍ به يك شيرفلكه و فشارسنج براى تنظـيم دبسى 


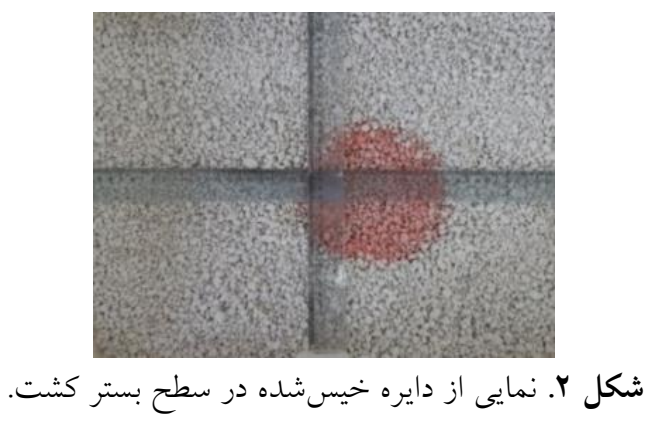

Fig. 2. Plan of the wetting circle on the surface of the growth medium.

$$
\text { جدول ب. تجزيه واريانس كمّيتهاى اندازهخيرىشده. }
$$

Table 3. Variance analysis of the measured quantities.

\begin{tabular}{|c|c|c|c|c|c|c|}
\hline \multicolumn{5}{|c|}{$\begin{array}{l}\text { ميانخين مربعات } \\
\text { Mean squared }\end{array}$} & \multirow{2}{*}{$\begin{array}{l}\text { Dرجه آزادى } \\
\text { DF }\end{array}$} & \multirow{2}{*}{$\begin{array}{c}\text { منابع تغييرات } \\
\text { Sum of squares }\end{array}$} \\
\hline $\mathrm{V}_{\text {wet }}$ & $\mathrm{MS}_{\mathrm{w}}$ & $\mathrm{MD}_{\mathrm{w} 20}$ & $\mathrm{MD}_{\mathrm{w} 10}$ & $V_{\text {water }}$ & & \\
\hline $275.36^{* *}$ & $988180.3^{* *}$ & $454.82 * *$ & $349.92 * *$ & $33.62 * *$ & 8 & بستر (Substrate) بت \\
\hline $35.31 * *$ & $53115.14^{\mathrm{ns}}$ & $178.58 * *$ & $204.6^{* *}$ & $18.05 * *$ & 2 & دبى (Discharge) \\
\hline $28.70 * *$ & $120364.9^{* *}$ & $33.24 * *$ & $37.5^{* *}$ & $4.40 * *$ & 16 & بستر × دبى (Substrate × Discharge) \\
\hline 4.37 & 19023.50 & 12.66 & 9.61 & 1.08 & 54 & خطاى آزمايش (Error) \\
\hline 17.54 & 18.27 & 11.31 & 10.9 & 23.45 & $(\mathrm{Cc}$ & ضريب تغييرات (icient of variation) \\
\hline \multicolumn{7}{|c|}{ 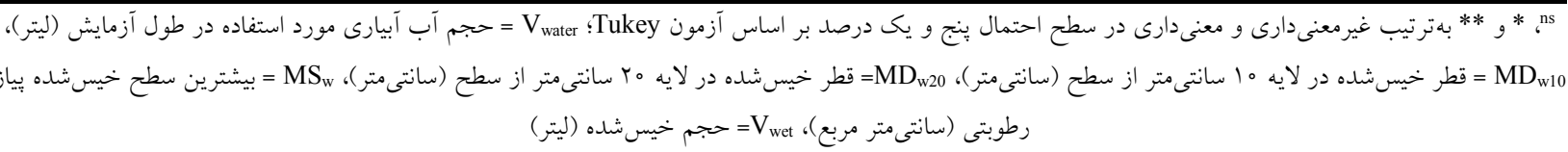 } \\
\hline
\end{tabular}

$\mathrm{MD}_{\mathrm{w} 10}=$ wetting diameter in layer $10 \mathrm{~cm}$ from the surface $(\mathrm{cm}), \mathrm{MD}_{\mathrm{w} 20}=$ wetting diameter in layer 20 from the surface $(\mathrm{cm}), \mathrm{MS}_{\mathrm{w}}=$ maximum wetting area $\left(\mathrm{cm}^{2}\right), \mathrm{V}_{\text {wet }}=$ wetting volume (liter)

با انتقال تصاوير الكوى توزيع رطوبت در عمـقهـاى مشـخص، به نــرمافـزار كرافـر (Grapher)، مختصـات جبهـهـ رطـوبتى در عمقهاى مختلف مشخص شد. سيس بهمنظور تعيين ابعاد جبهه

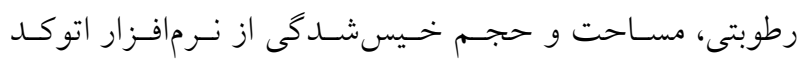
(AutoCAD Civil 3D 2013) تحليل دادهها با استفاده از نرم|فـزار SAS نسـخه r/r در قالـب

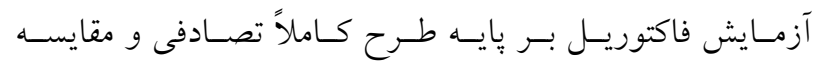

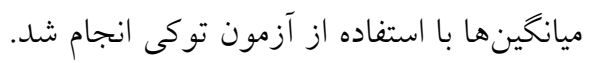

\section{نتايج و بحث}

نتايج تجزيه واريانس دادهها در جـدول (r) و مقايسـه ميـانخين كميّيتها نيز در جدول (Y) درج شده است. نتايج نشان داد كه
كه زهآب از انتهاى بستر خارج شـد. بـا اسـتفاده از ميـزان دبـى

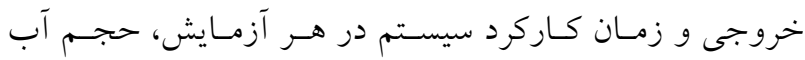
ورودى به بسترها بهدست آمد. يس از اتمام آبيارى، مـواد بسـتر از سطح بهصورت لايههاى با ضخامت ه سانتى متر برداشت شد

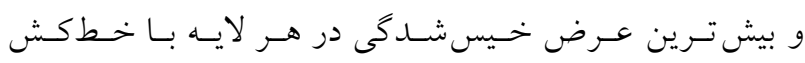
اندازهذيرى شده و توسط دوربين تصويربردارى شـــ. هـر مـــل

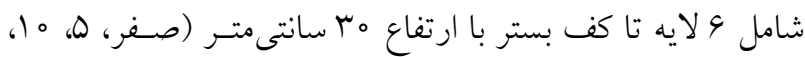
ها، مب و ه ا سانتى متر از سطح) بود.

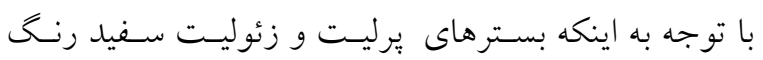
بودند براى تشخيص جبهه رطوبتى، به آب ماده رنخى خـوراكى افزوده شد. شكل (Y) نمونهاى از دايره خيسشده لايسه سـطى توسط ماده رنكى را نشان مىدهد. 


$$
\text { جدول ثا. مقايسه ميانخين اثر تيمارهاى آزمايشى بر كمّيتهاى اندازهيرىشده. }
$$

Table 4. Mean comparisons of the measured quantities as affected by the experiment treatments.

\begin{tabular}{|c|c|c|c|c|c|}
\hline \multicolumn{5}{|c|}{$\begin{array}{l}\text { ميانخينها } \\
\text { Means }\end{array}$} & \multirow{2}{*}{$\begin{array}{c}\text { تيمارها } \\
\text { Treatments }\end{array}$} \\
\hline $\mathrm{V}_{\text {wet }}$ & $\mathrm{MS}_{\mathrm{w}}$ & $\mathrm{MD}_{\mathrm{w} 20}$ & $\mathrm{MD}_{\mathrm{w} 10}$ & $\mathrm{~V}_{\text {water }}$ & \\
\hline $10.06^{\mathrm{c}}$ & $704.35^{\mathrm{c}}$ & $31.83^{\mathrm{b}}$ & $27.56^{\mathrm{b}}$ & $3.35^{\mathrm{c}}$ & P100 \\
\hline $14.58^{\mathrm{b}}$ & $947.18^{\mathrm{b}}$ & $38.28^{\mathrm{a}}$ & $33^{a}$ & $5.17^{\mathrm{b}}$ & P95C05 \\
\hline $16.42^{\mathrm{ab}}$ & $1006.69^{\mathrm{ab}}$ & $37.42^{\mathrm{a}}$ & $34.11^{\mathrm{a}}$ & $5.74^{\mathrm{b}}$ & P90C10 \\
\hline $19.57^{\mathrm{a}}$ & $1228.91^{\mathrm{a}}$ & $40.17^{\mathrm{a}}$ & $35.78^{\mathrm{a}}$ & $7.26^{\mathrm{a}}$ & P85C15 \\
\hline $18.85^{\mathrm{a}}$ & $1122.26^{\mathrm{ab}}$ & $38^{\mathrm{a}}$ & $35.89^{\mathrm{a}}$ & $7.55^{\mathrm{a}}$ & P80C20 \\
\hline $8.01^{\mathrm{cd}}$ & $496.2^{\mathrm{cd}}$ & $25.39^{\mathrm{c}}$ & $24^{\mathrm{bc}}$ & $2.99^{c}$ & P97.5Z2.5 \\
\hline $5.94^{\mathrm{d}}$ & $386.35^{d}$ & $24.06^{\mathrm{c}}$ & $21.44^{\mathrm{c}}$ & $2.52^{\mathrm{c}}$ & P95Z05 \\
\hline $6.47^{\mathrm{d}}$ & $424.27^{\mathrm{d}}$ & $23.44^{\mathrm{c}}$ & $21.61^{\mathrm{c}}$ & $2.58^{\mathrm{c}}$ & P92.5Z7.5 \\
\hline $7.07^{\mathrm{cd}}$ & $452.87^{d}$ & $24.56^{\mathrm{c}}$ & $22.72^{\mathrm{c}}$ & $2.9^{\mathrm{c}}$ & P90Z10 \\
\hline $11.82^{\mathrm{ab}}$ & $739.7^{\mathrm{a}}$ & $32.73^{\mathrm{a}}$ & $29.61^{\mathrm{a}}$ & $4.58^{\mathrm{a}}$ & Q2 \\
\hline $13.07^{\mathrm{a}}$ & $802.25^{\mathrm{a}}$ & $33.15^{\mathrm{a}}$ & $30.44^{\mathrm{a}}$ & $5.2^{\mathrm{a}}$ & Q3 \\
\hline $10.78^{b}$ & $714.41^{\mathrm{a}}$ & $28.5^{\mathrm{b}}$ & $25.31^{\mathrm{b}}$ & $3.52^{\mathrm{b}}$ & Q4 \\
\hline
\end{tabular}

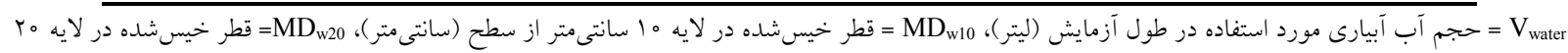

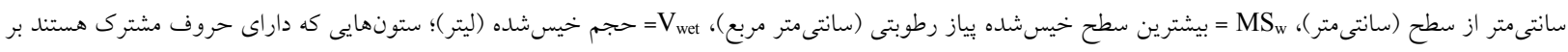
اساس آزمون Tukey در سطح ه درصد اختلاف معنى دار ندارند.

$\mathrm{V}_{\text {water }}=$ volume of irrigation water (liter), $\mathrm{MD}_{\mathrm{w} 10}=$ wetting diameter in layer $10 \mathrm{~cm}$ from the surface $(\mathrm{cm}), \mathrm{MD}_{\mathrm{w} 20}=$ wetting diameter in layer 20 from the surface $(\mathrm{cm}), \mathrm{MS}_{\mathrm{w}}=$ maximum wetting area $\left(\mathrm{cm}^{2}\right), \mathrm{V}_{\text {wet }}=$ wetting volume (liter); Bars with similar letters are not significantly different $($ Tukey, $p<0.05)$.

دبى ب ليتر بر ساعت، تغييرى در حجم آب آبيارى مـورد اسـتفاده ايجاد نمىشود و بين بسترهاى حاوى زئوليت و كوكوييت تفاوت معنادارى وجود ندارد. در شرايط دبى بل ليتر بر ساعت بـيشترين حجم آب مربوط به بسترهـاى حساوى كوكويــت بـود و تفـاوت معنى دارى بين درصدهاى مختلف كوكوييـت وجــود نداشـت. در

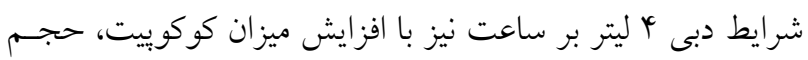

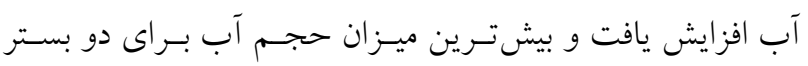

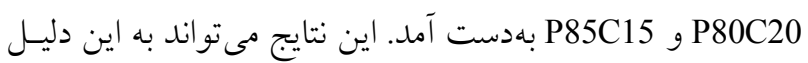

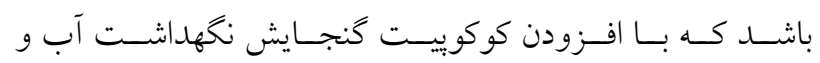

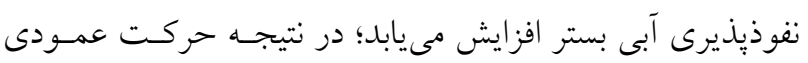

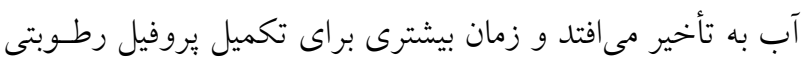

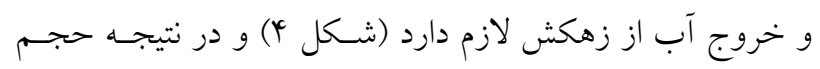

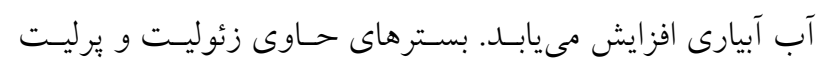

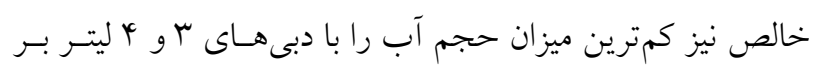
ساعت داشتند كه با نتايج مصلحى (N) همخوانى داشت.
اثر بستر بر همه صفات اندازه گيرىشده و اثر دبى بـهـجـز بـراى بيشترين سطح خيس شده در بين لايه ها، بر بقيسه كمّيـتهـا در سطح احتمال يك درصد معنى دار شدند. همجنين اثر برهمكنش

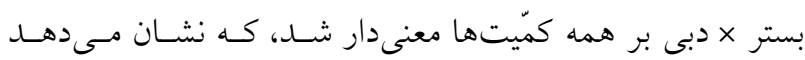
بسترها در دبى هاى مختلف بهطور متفاوت عمل مى كنند. تغييرات حجم آب آبيارى همان گونه كه بيان شد با استفاده از دبى خروجى قطرهجهــان و مدت زمان آبيارى، حجم آب آبيارى تا زمان قطع جريان كـه در واقع زمان خروج اولين قطره از زهكش است، بهدست مسى آيــ.

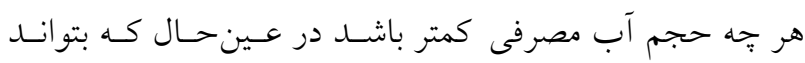

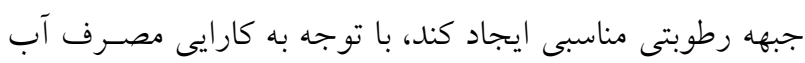
مطلوبتر است. مقايسه اثر برهم كنش نوع بستر و دبى قطرهجهـان بـر حجـم

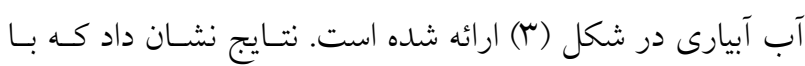




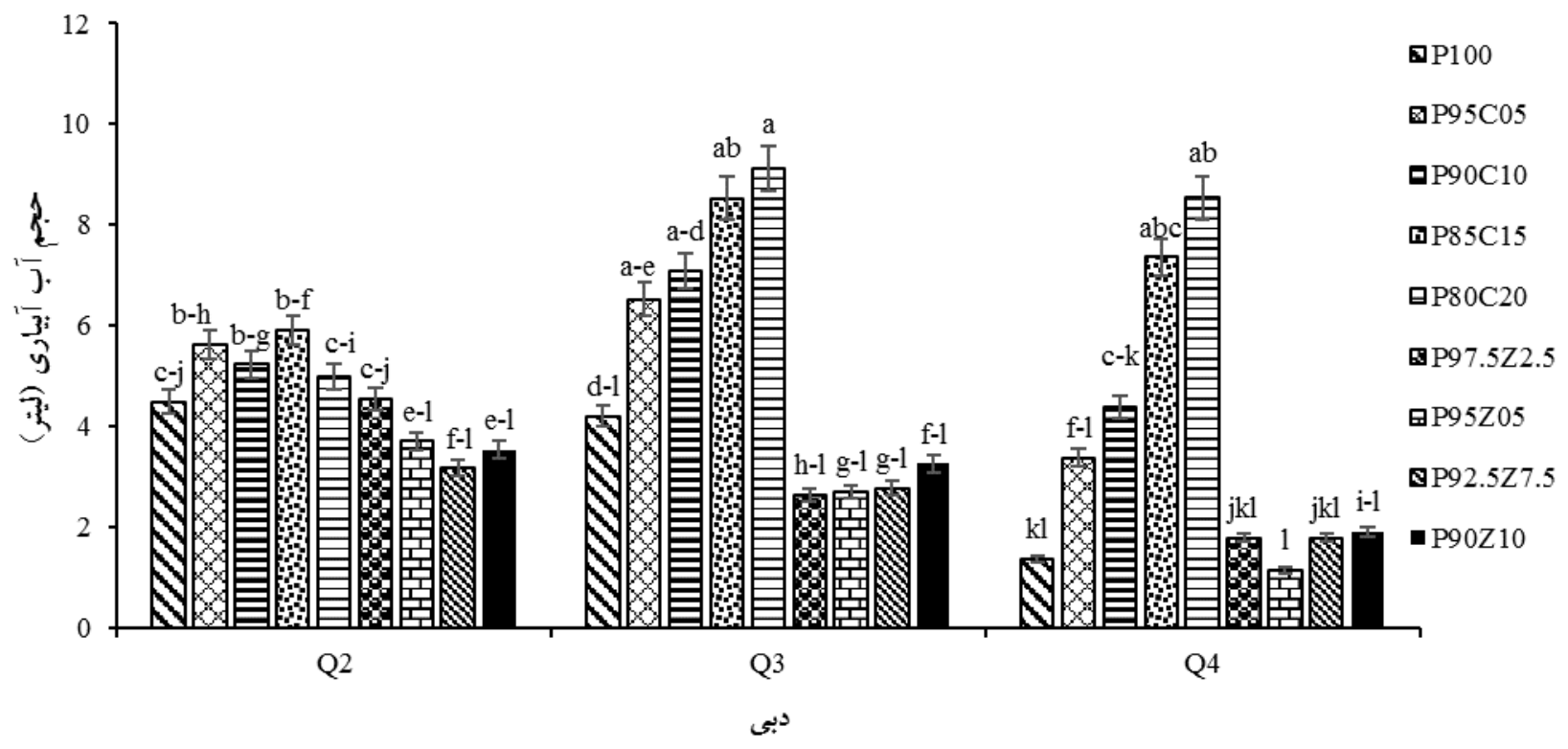

شكل r. مقايسه ميانكين اثر برهم كنش نوع بستر كشت × دبى قطرهجكان بر حجم آب آبيارى؛ ستونهايى كه داراى حروف مشترى هستند بر

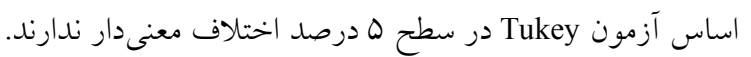

Fig. 3. Mean comparison of the interaction effect of the growth medium type $\times$ emitter discharge on the irrigation water volume; bars with similar letters are not significantly different (Tukey, $p<0.05$ ).

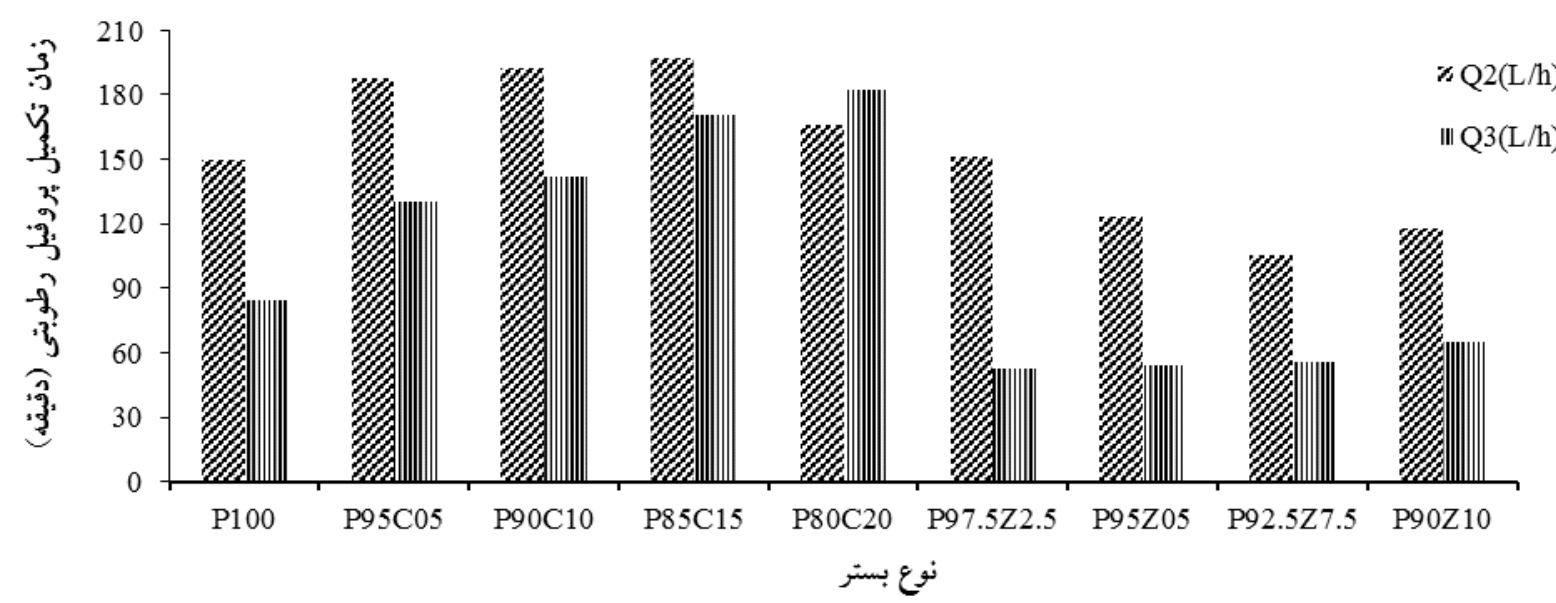

شكل †. زمان آبيارى در تيمارهاى مختلف.

Fig. 4. Irrigation time in different treatments.

آب را دارند، براى گستردگى سطح خيسشــده بررسى شـدند.

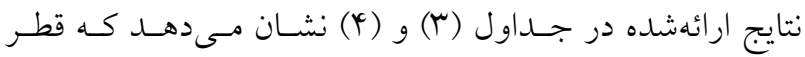
خيسشده در لايه ه ا سانتى مترى با افزودن كوكوييت به برليـت بستر افزايش مىيابد، اما افزايش ميزان درصد كوكوبيت تـأثيرى

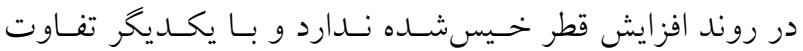
معنى دارى ندارند. قطر خيسشده در عمق • ا سانتى مترى براى

$$
\begin{aligned}
& \text { تأثير دبى و تركيب بستر كشت بر قطر خيسشده در لايه ها } \\
& \text { سانتى مترى از سطح } \\
& \text { اين يزّوهش براى بسترهاى كشت مورد استفاده در كشـتهـاى }
\end{aligned}
$$

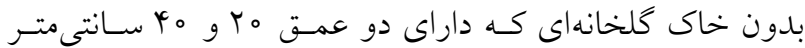

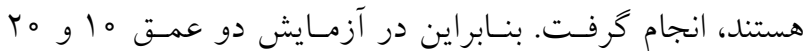

$$
\begin{aligned}
& \text { سانتى متر به عنوان عمق هايى كه بيش ترين حجم ريشه و جـــبـ }
\end{aligned}
$$




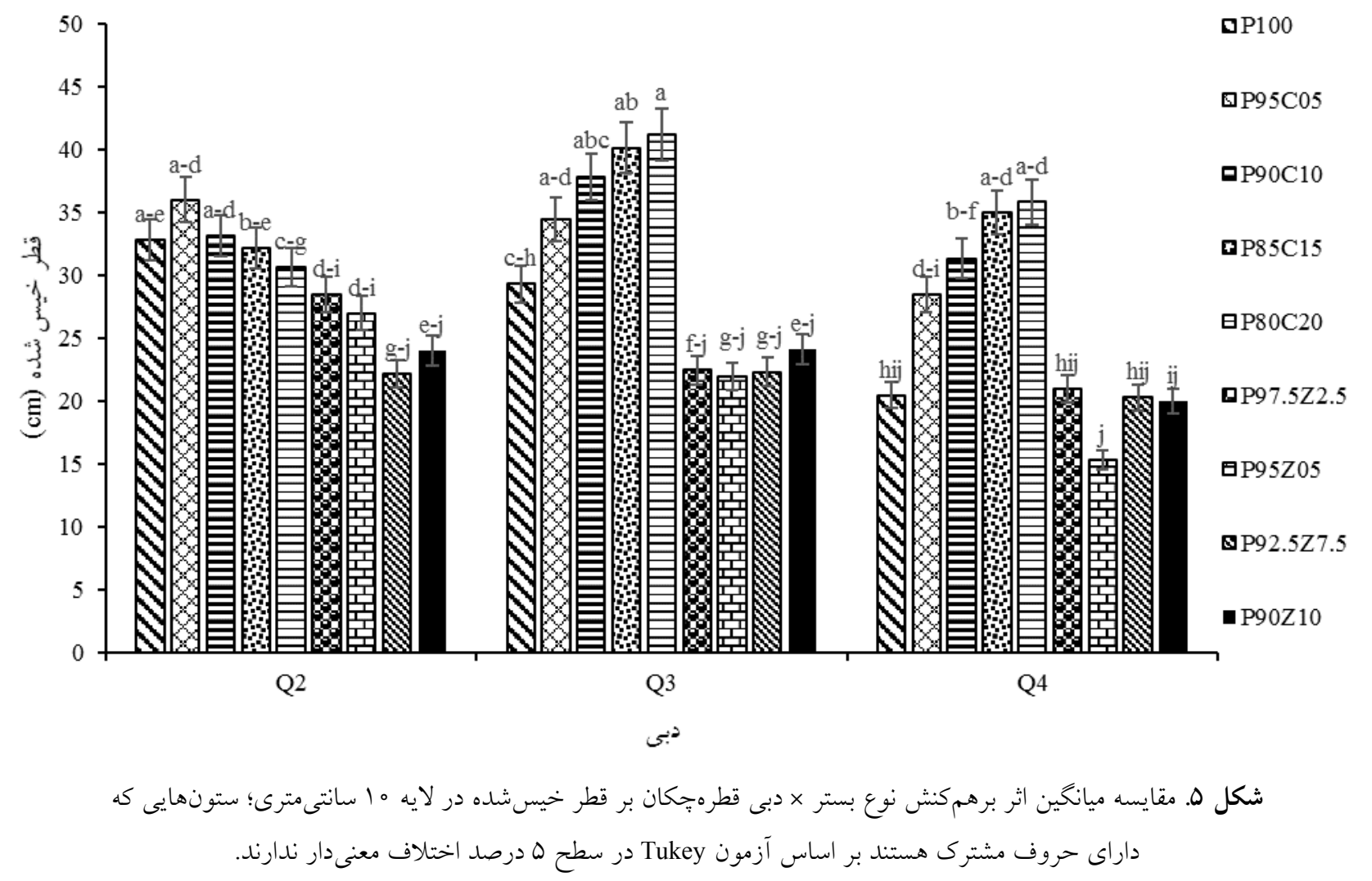

Fig. 5. Mean comparison of interaction effect of type of growth medium $\times$ emitter discharge on wetting diameter in layer $10 \mathrm{~cm}$; Bars with similar letters are not significantly different (Tukey, $p<0.05$ ).

نوع بستر و دبى قطرهجهان بر بيشترين قطر خيسشده در لايـه. ها سانتى متر در شكل (ه) ارائه شده است. بهطور كلى نتسايج نشان مىدهد افزودن كوكوييت زئوليت بهترتيب باعـث افـزايش

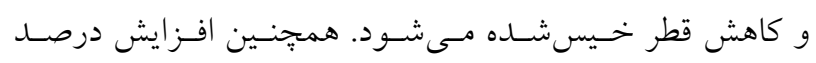
كوكوييت در بستر تأثيرى بر افزايش قطر خيسشده نــارد ولى لـ افزايش درصد زئوليت باعث كاهش قطر خـيسشــده مسى شـود. بيشترين و كمترين قطر خيس شده در ايسن لايسه بـهترتيـب در تيمارهاى تركيبى بستر P80C20 با دبى ب ليتر بر ساعت و بسـتر

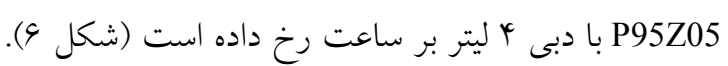
نتايج مقايسه كروهى در شكل (V) نشان مسىدهـد كـه قطر خيسشده در بستر حاوى بِرليت خالص نسبت بـه بسـتر داراى زئوليت به طور معنى دارى بيشتر و نسبت به كوكوييت كمتر بـود

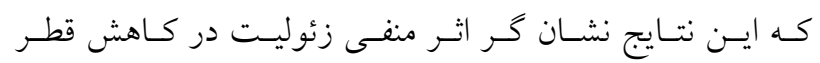
خيس شدگى است.
تيمارهاى داراى كوكوييت بيش از Vo درصد طول جعبه كشـت

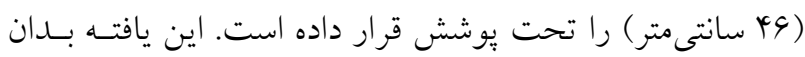
مفهوم است كه در كشتهاى تكىرديفه حتى در بستر كشتهاى

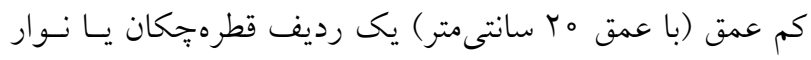

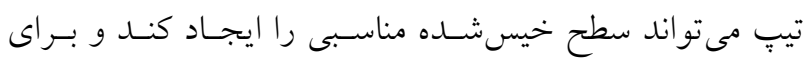

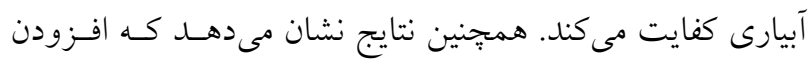
بين ه تا ه ا درصد كوكوييت براى كسترش سطح خيس شده در بستر كشت كـافى اسـت. ولى نتـايج جــاول (r) و (†) بـراى زئوليت نشان مىدهد كه افـزايش زئوليـت باعـث كـاهش قطـر خيس شده در عمق ه ا سانتى مترى شده است. قطر خــيس شـده در عمق • ا سانتىمترى براى تيمارهاى داراى زئوليت در حدود مه درصد طول جعبه كشت را تحت بوشـش قـرار داده اسـت. اين نتيجه بدان مفهوم است يك رديف قطرهجِكان يا نوار تيـٍِ در بستر كشت داراى تركيب زئوليت، كافى نيست و دو رديـف

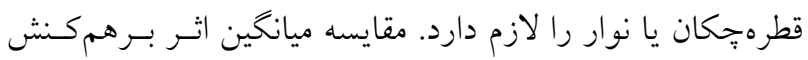




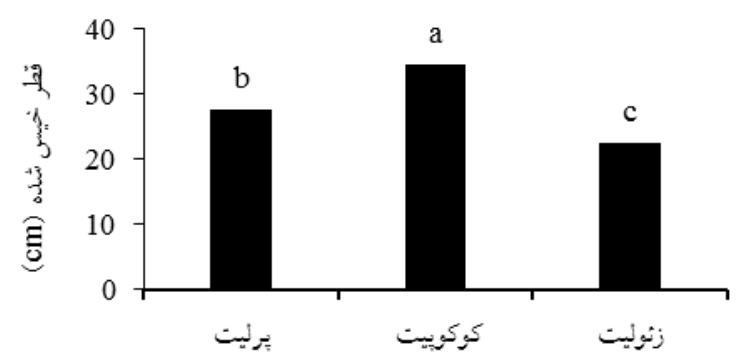

شكل 9. مقايسه كروهى ميانكَين بسترهاى كشت مختلف براى قطر خيسشده در لايه ه 1 سانتىمترى؛ ستونهاى با حروف متفاوت بر اساس

آزمون Tukey در سطح ه درصد اختلاف معنى دار دارند.

Fig. 6. Group mean comparison of different growth media for the wetting diameter in the $10 \mathrm{~cm}$ layer; bars with different letters are significantly different (Tukey, $p<0.05$ ).

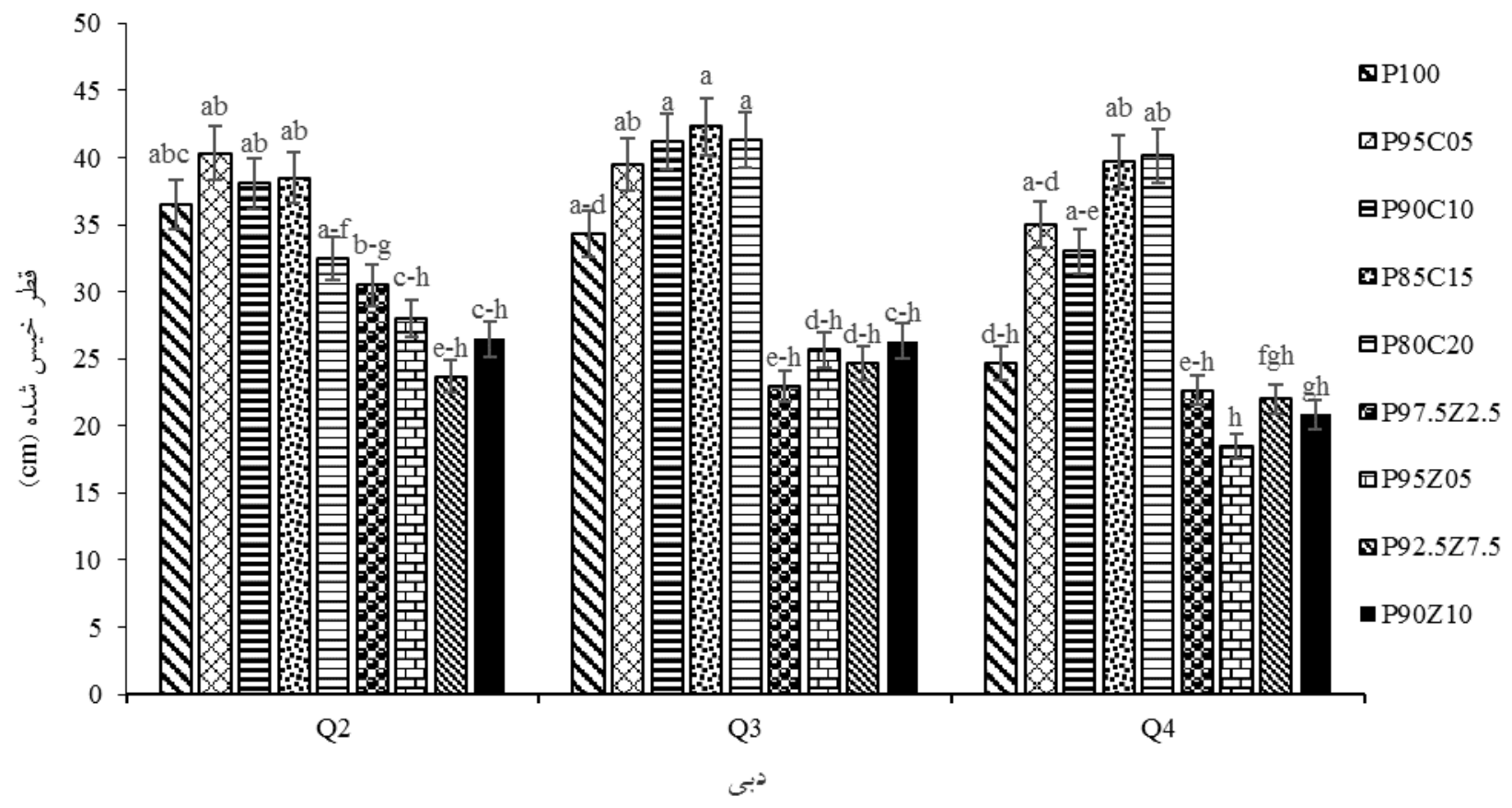

شكل V. مقايسه ميانخين اثر برهمكنش نوع بستر كشت × دبى قطرهجكان بر قطر خيسشده در لايه هY سانتىمترى؛ ستونهايى كه داراى حروف مشترى هستند بر اساس آزمون Tukey در سطح ه درصد اختلاف معنى دار ندارند.

Fig. 7. Mean comparison of the interaction effect of the growth medium type $\times$ emitter discharge on the wetting diameter in the 20 $\mathrm{cm}$ layer; bars with similar letters are not significantly different (Tukey, $p<0.05$ ).

در همين لايه بود. نتايج ارائهشـده در جـداول (Y) و (Y) نشـان

مىدهد كه قطر خيسشده در لايه مب سانتى مترى نيز مانند لايسه

•ا سانتىمترى با افزودن كوكوبيت به يرليت بستر افزايش مىيابـد،

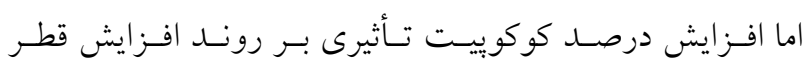

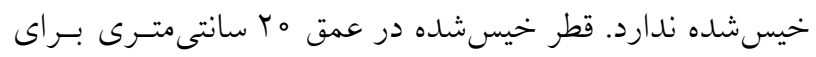

تيمارهاى داراى كوكوييت بيش از م1 درصد سطح جعبه كشت
تأثير دبى و تركيب بستر كشت بر قطر خيسشده در لايه سانتى مترى از سطح در تمامى آزمايش ها كف بستر (لايه هr سانتىمتر) تقريباً كامـل خيسشده بود، به همين دليل در اندازه خيرى قطر خيسشده، اين

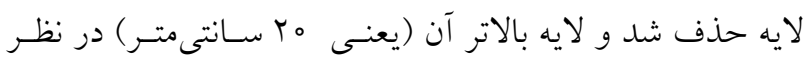
كرفته شد كه بيشترين قطر خيسشده هم در تمامى آزمايشهـا 


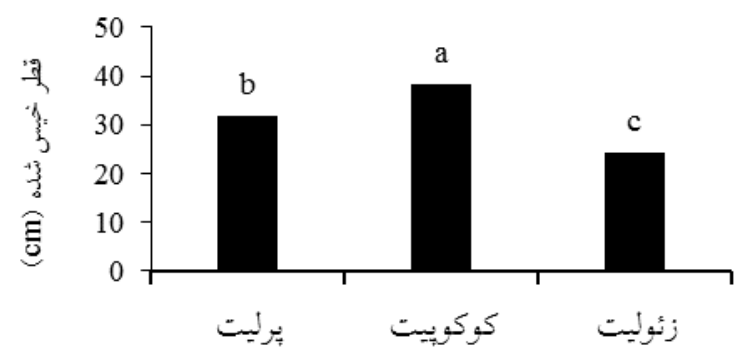

شكل ^. مقايسه گروهى ميانخين بسترهاى كشت مختلف براى قطر خيسشده در لايه م سانتىمترى؛ ستونهاى با حروف متفاوت بر اساس

آزمون Tukey در سطح ه درصد اختلاف معنى دار دارند.

Fig. 8. Group mean comparison of different growth media for the wetting diameter in the $20 \mathrm{~cm}$ layer; bars with different letters are significantly different (Tukey, $p<0.05$ ).

نتايج مقايسه گروهى نيز نشان داد كه مشابه عمق ه ا سانتى متـر قطر خيسشده در بستر حاوى برليت خالص نسبت به بسترهاى حاوى زئوليت بهطور معنى دارى بيشـتر و نسـبت بـه كوكوييـت

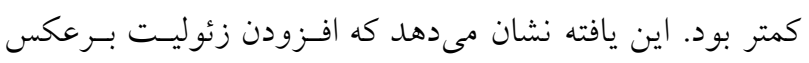
كوكوييت نمىتواند باعث افزايش قطر خـيسشـــه و در نتيجـهـ ايجاد اثر مطلوبى شود (شكل ^). با افزايش كوكوبيت به برليـت

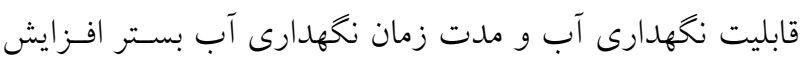
مىيابد و در نتيجه عرض خيسشدگى افزايش يافت كه با نتايج اسدى و همكاران (r) همخوانى داشت.

تأثير دبى و تركيب بستر كشت بر حجم خيس شـده بروفيسل رطوبتى با توجه به جداول (r) و (Y)، نتايج اثر اصلى نـوع بسـتر نشـان

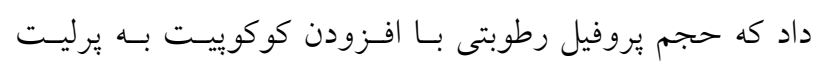

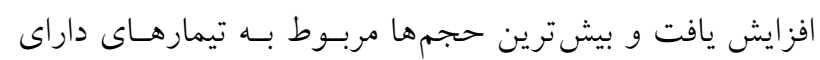

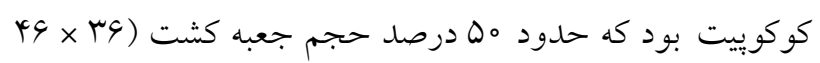

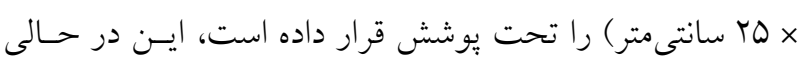

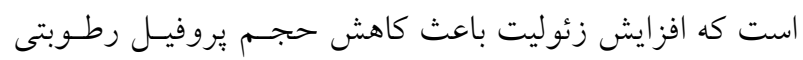

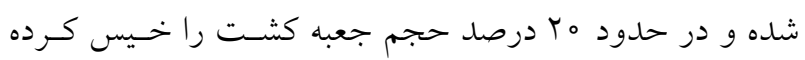

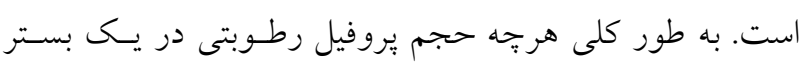

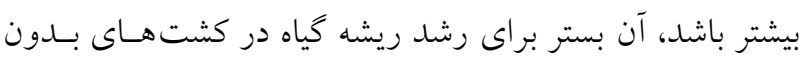

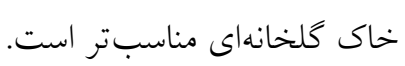

را تحت يوشش قـرار داده اسـت. ايسن بـــان مفهـوم اسـت كـه در

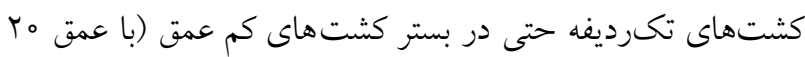

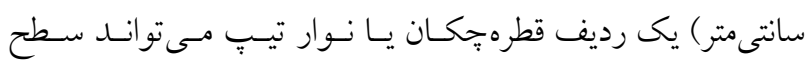

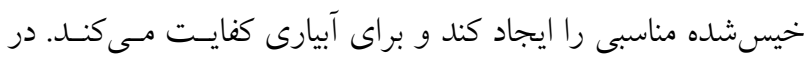

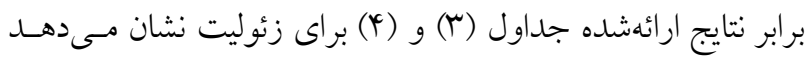

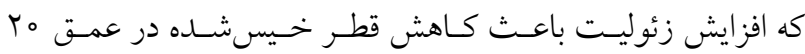

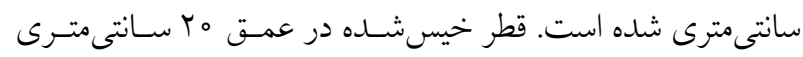
براى تيمارهاى داراى زئوليـت در حسـود مه درصــ طـول جعبـهـ كشت را تحت بوشش قرار داده است، اين بــان مفهـوم اسـت كـهـ يكى رديف قطرهجان يا نوار تيٍّ در بستر كشتى كه زئوليت بهكار رفته كافى نيست و دو رديف قطرهجكان يا نوار را لازم دارد.

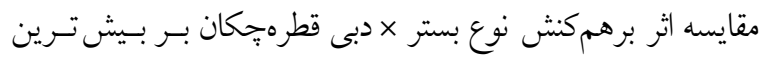

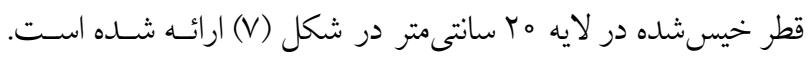

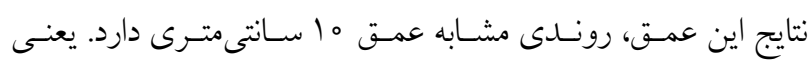

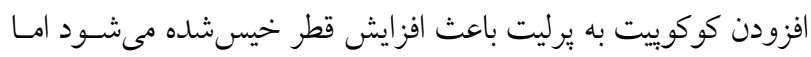

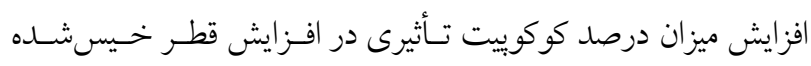

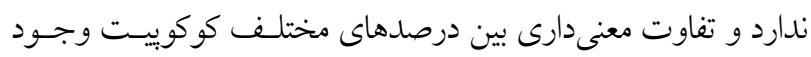

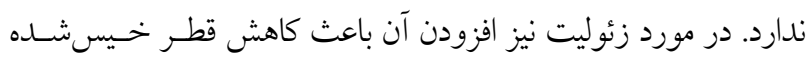

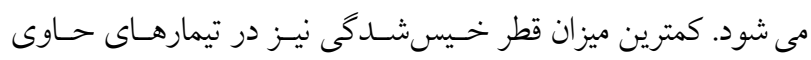

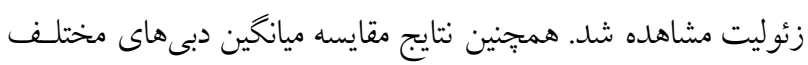

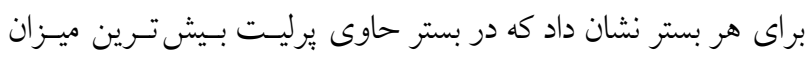

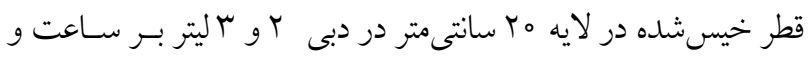

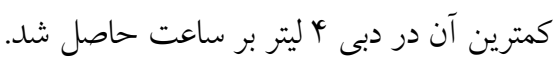




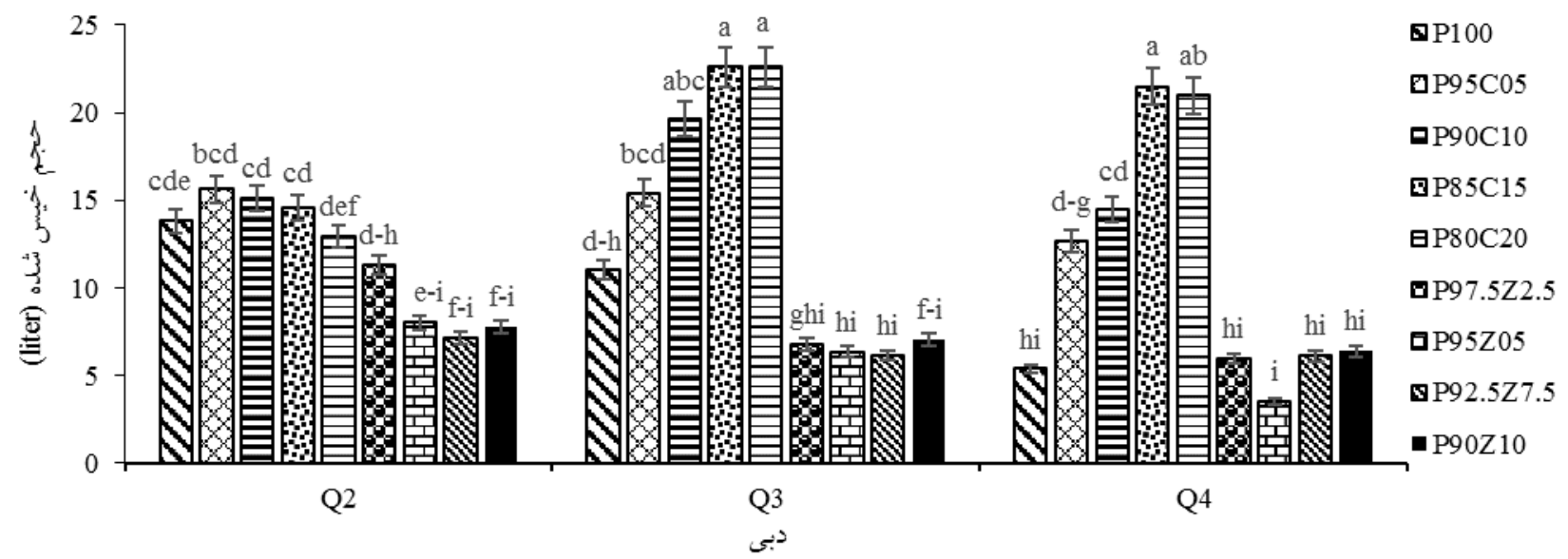

شكل 9. مقايسه ميانكَين اثر برهم كنش نوع بستر × دبى قطرهجكان بر حجم بروفيل رطوبتى؛ ستونهايى كه داراى حروف مشترك هستند بر اساس

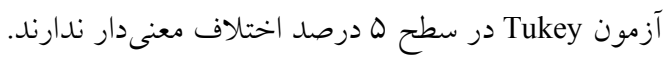

Fig. 9. Mean comparison of interaction effect of type of growth medium e $\times$ emitter discharge on wetting volume; Bars with similar letters are not significantly different (Tukey, $p<0.05$ ).

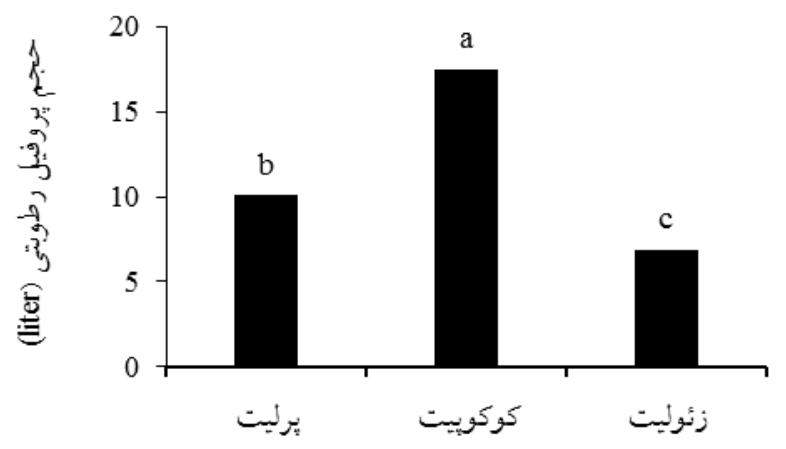

شكل • ا. مقايسه كروهى ميانكَين بسترهاى مختلف براى حجم يروفيل رطوبتى؛ ستونهاى با حروف متفاوت بر اساس آزمون Tukey در سطح ه هن درصد اختلاف معنى دار دارند.

Fig. 10. Group mean comparison of different substrates for wetting volume; Bars with different letters are significantly different (Tukey, $p<0.05$ ).

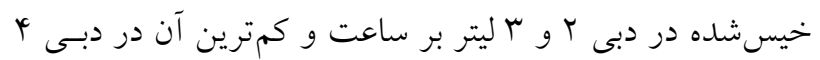

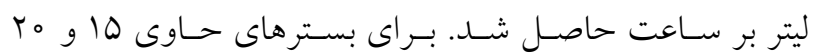

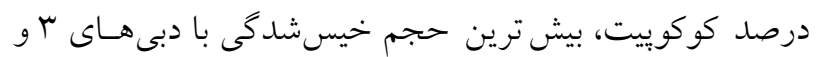

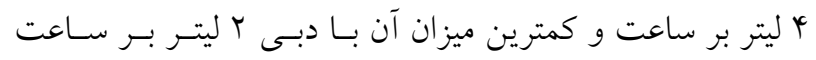

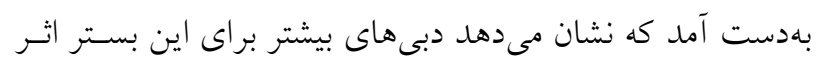

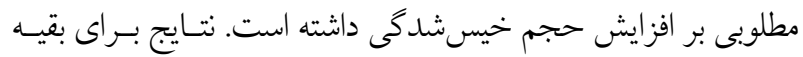
بسترها حاكى از غيرمعنى دارى تفاوت بين دبى ها بود (شكل 9. 9.

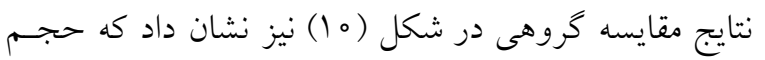
خيسشده در بستر يرليت خالص بـهــور معنسى دارى بيشتر از

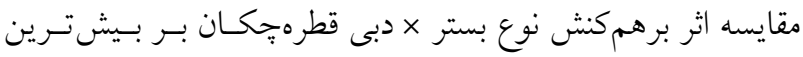

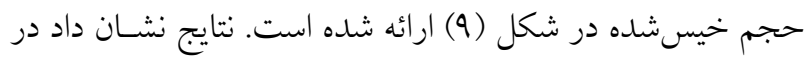

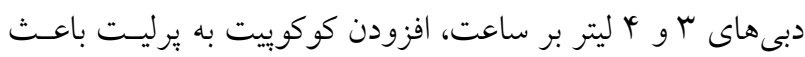

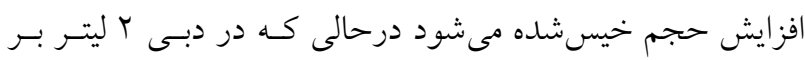

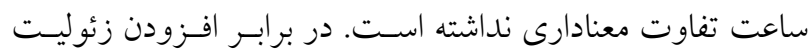

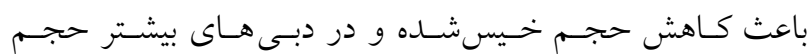

$$
\begin{aligned}
& \text { خيسشدى با افزايش زئوليت بيشتر كاهش مى يابد. }
\end{aligned}
$$

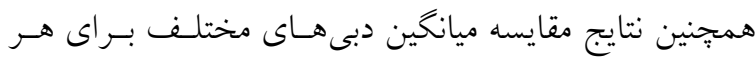

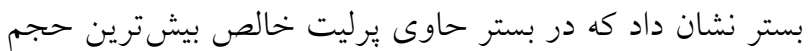




$$
\begin{aligned}
& \text { بر اساس نتايج بهدست آمده بروفيل رطوبتى در بسـترهاى حساوى }
\end{aligned}
$$

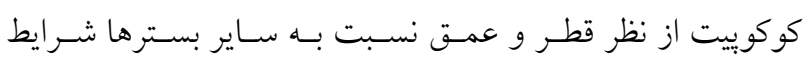

$$
\begin{aligned}
& \text { مناسبترى براى توزيع و نخهاشداشت آب در ناحيه ريشـهـ داشـتند. }
\end{aligned}
$$

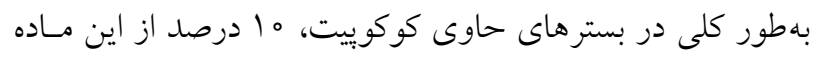

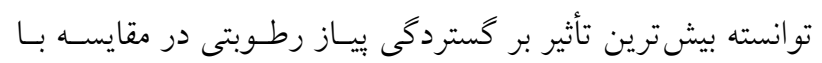

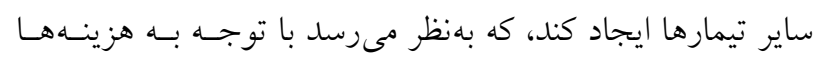

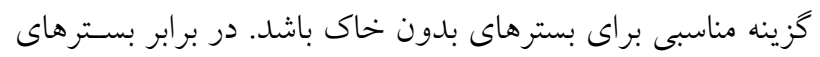

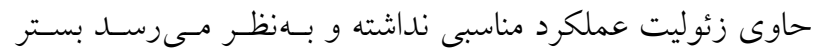

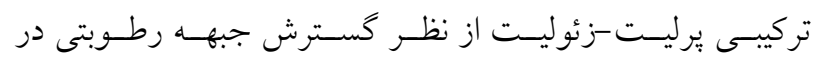

$$
\begin{aligned}
& \text { بسترهاى كشت بلدون خاك گزينه مناسبى نيست. }
\end{aligned}
$$

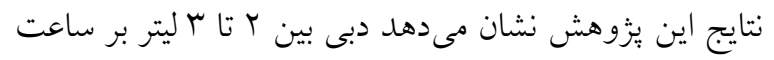

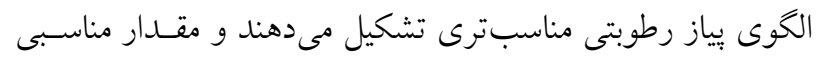

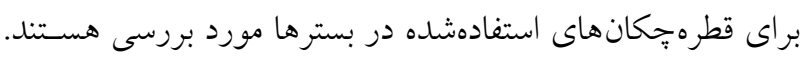

$$
\begin{aligned}
& \text { بلهنر مىرسد دبى هاى بيشتر تلفات زهآب بيشـترى ايجـاد كنـــ. }
\end{aligned}
$$

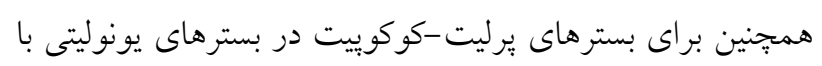

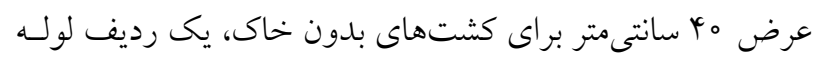

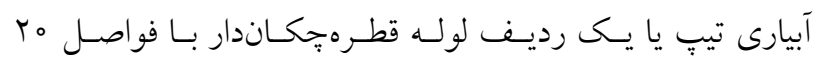

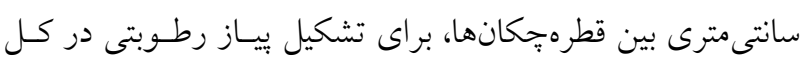

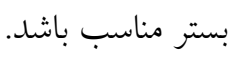

$$
\begin{aligned}
& \text { بسترهاى حاوى زئوليت بود بهدليل اينكه زئوليـت آب را بـراى }
\end{aligned}
$$

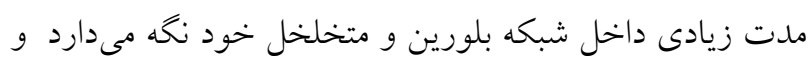

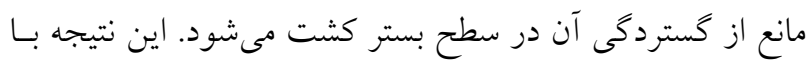

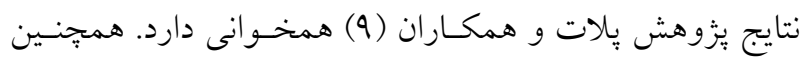

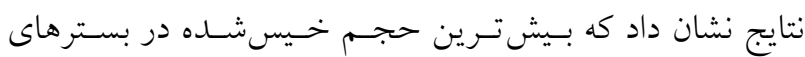

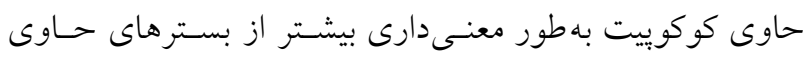

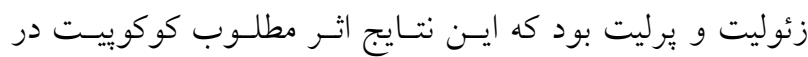

$$
\begin{aligned}
& \text { افزايش حجم بياز رطوبتى را بر خلاف زئوليت نشان مسدهــــ. }
\end{aligned}
$$

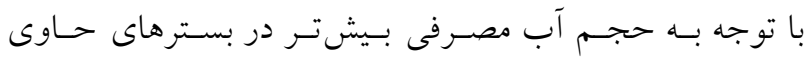

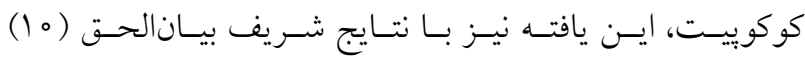

$$
\begin{aligned}
& \text { همخوانى داشت. } \\
& \text { نتيجه گيرى } \\
& \text { در اين بزوهش اثر سه دبى قطرهجانان در بسترهاى كشت تركيبى }
\end{aligned}
$$

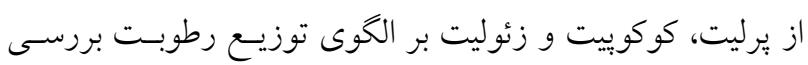

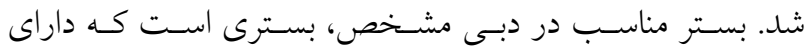

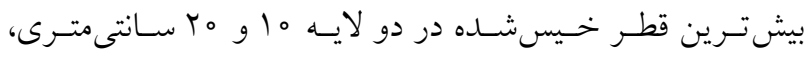

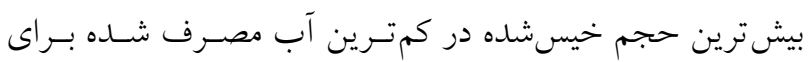

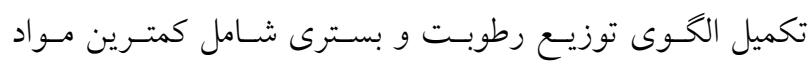

$$
\begin{aligned}
& \text { مصرفى وارداتى كرانقيمت باشد. }
\end{aligned}
$$

\section{منابع مورد استفاده}

1. Altman, A., Freudenberg, D., 1983. Quality of Pelargonium graveolens cutting as affected by the rooting medium. Scientia Horticulturae. 19: 379-385.

2. Aminalroayaei Yamini, A. 2015. Evaluation of Superabsorbent A200 and Zeolite on Improving Moisture Distribution Patterns in Drip Irrigation in Two Soil Textures. MSc Thesis, Shahrekord University. Shahrekord, Iran. (in Persian with English abstract)

3. Asadi, Z., and N. Yazdan Panah. 2015. Modified wetting distribution and reducing used water by employing super absorbent Herbozorb and Cocopeat in drip irrigation. $2^{\text {th }}$ National Conference on the Application of Science and New Ttechnology in Agriculture, Natural Resources and The Environment. Meybod, Iran. (in Persian).

4. Esmaeili, E. 2015. Evaluation of Effect of Different Discharges on Moisture Patterns usinng T-Tape Irrigation in Sloping Lands. MSc Thesis, Shahid Chamran University of Ahvaz. Ahvaz, Iran. (in Persian with English abstract).

5. Heidari, Z., Farasati, M., Ghobadian, R., 2018. Effect of discharge on water pattern distribution in surface drip irrigation and simulation it with HYDRUS-2D model. Journal of Irrigation and Water Engineering. 32: 132-144. (in Persian with English abstract)

6. Iqbal, M., Ghumman, A.R., Hashmi, H.N., 2017. Study of wetting pattern under drip-emitter using sand box model and empirical equations. Pakistan Journal of Agricultural Sciences. 54: 699-709.

7. Jensen, M., 2013. What is hydroponics. Controlled Environment Agriculture Center. Arizona Board of Regents, University of Arizona, Tucson. 
8. Moslehi, M., 2014. Determining water consumption and the effect of saline water on lettuce characteristics in different soilless substrates. MSc Thesis, Isfahan University of Technology. Isfahan, Iran.

9. Polat, E., Karaca, M., Demir, H., Onus, A.N., 2004. Use of natural zeolite (clinoptilolite) in agriculture. Journal of Fruit and Ornamental Plant Research. 12(1): 183-189.

10. Sharif Bayanolhagh, M.H., 1997. Wetting Front Advance from a Point Source in Sloping Lands. MSc Thesis, Isfahan University of Technology. Isfahan, Iran. (in Persian with English abstract)

11.Zhigang, L., Qinchao, X., 2018. Wetting patterns estimation in cultivation substrates under drip irrigation. Desalination and Water Treatment. 112: 319-324. 


\title{
The Effect of Dripper Discharge and Growth Medium on Wetting Distribution Patterns in Soilless Growth Media
}

\author{
S.A. Ahmadi Foroushani ${ }^{1}$, M. Ghobadinia ${ }^{1 *}$, R. Barzegar ${ }^{2}$ and R. Fattahi Nafchi ${ }^{1}$
}

(Received: 19 August 2020; Accepted: 10 January 2021)

\begin{abstract}
Determining the wetting distribution pattern is essential for the proper design of drip irrigation systems. Identifying the pattern of wetting distribution enhances the efficiency of the irrigation system and water use. This study was conducted to determine the wetting distribution caused by a point source and compare it among different growth media as a factorial based on a completely randomized design with three replications. The first factor, the growth medium type, included 9 levels with a combination of zeolite, perlite and cocopeat; the second one consisted of the dripper discharge at three levels of 2, 3 and 4 liters per hour. The results showed that the effects of medium type and the interaction of the medium $\times$ dripper discharge on all measured quantities (volume of irrigation water, wetting diameter in 10 and $20 \mathrm{~cm}$ layers from the surface, maximum wetting area and wetting volume) were significant. The effect of the dripper discharge on all quantities except the maximum wetting area was significant too. The addition of $10 \%$ cocopeat to perlite had a positive effect on the wetting distribution pattern and increased the wetting volume by $79 \%$ at a discharge of 3 liters per hour; however, zeolite did not perform well, as compared to cocopeat, reducing the wetting volume by $30 \%$. In general, the appropriate dripper discharge in all growth media was 3 liters per hour. The discharges of 2 and 3 liters per hour are suitable and cocopeat-perlite medium with a composition percentage of 20-80 led to forming a suitable wetting distribution pattern.
\end{abstract}

Keywords: Drip Irrigation, Wetting distribution patterns, Soilless growth media, Zeolite, Cocopeat.

Background and Objective: Wetting distribution pattern is an important feature that should be considered when designing the irrigation system. Iqbal et al. (2) conducted a study to identify the wetting pattern in different soil textures and discharges. Based on the results, the optimal discharge was 4 liters per hour for a sandy loam soil and 3 liters per hour for the other three soils. The wetting distribution patterns can guide designers in choosing the number, arrangement of droppers and pipes, and planting depth. Besides, the crop yield depends on the wetting area of the soil; therefore, by optimizing it, the crop yield can also be increased. The results of a study showed that the application of cocopeat increased the width and depth of wetting (3). The objective of this study was to determine the wetting distribution caused by a point source and compare it among different growth media.

Methods: This experiment was conducted in a physical model as a factorial based on a completely randomized design with three replications. The first factor, the growth medium type, included 9 levels with a combination of zeolite, perlite and cocopeat; the second one consisted of the dripper discharge at three levels of 2, 3 and 4 liters per hour. In order to select the appropriate amount of zeolite, cation exchange capacity (CEC) was used in cocopeat-like media was invoked. This was such that the CEC should be the same for both growth media. The average CEC of zeolite was twice of that in cocopeat, so the amount of zeolite used was about half of cocopeat. A rectangular physical model made of polystyrene with width, length and height of 40,50 and $35 \mathrm{~cm}$ was used. The depth of each model was divided to 6 layers of $5 \mathrm{~cm}$

1. Department of Water Engineering, Faculty of Agriculture, Shahrekord University.

2. Department of Horticulture, Faculty of Agriculture, Shahrekord University.

* Corresponding Author, Email: mahdi.ghobadi@gmail.com 
(zero, 5, 10, 15, 20 and $25 \mathrm{~cm}$ ). A water outlet was placed in the center of each model. The irrigation was continued until the drain came out of the bottom of the media. After irrigation, the media material was removed layer by layer from the surface with a thickness of $5 \mathrm{~cm}$ and the maximum wetting width in each layer was measured.

Results: The results showed that with a discharge of 4 liters per hour, water volume was raised with increasing cocopeat; this was because with the addition of cocopeat, the water holding capacity of the media increased. Media containing zeolite and pure perlite had the lowest water volume with the discharges of 3 and 4 liters per hour, which was consistent with the findings of Moslehi (3). The results also showed that the addition of cocopeat and zeolite increased and decreased the wetting diameter in 10 and $20 \mathrm{~cm}$ layers and the volume of wetting distribution patterns, respectively. Addition of cocopeat to perlite increased the water holding capacity of the media; as a result, the wetting width was increased, which was consistent with the results obtained by Asadi et al. (1). The wetting volume in pure perlite medium was higher than the substrate containing zeolite, because zeolite retains water in its porous lattice thus preventing its spread on the surface of the medium, which was consistent with the results of Polat al. (4).

Conclusions: An appropriate growth medium in a specific dripper discharge is one that led to forming a more suitable wetting distribution pattern with the most economical irrigation and importing used growth media. The wetting distribution pattern in the media containing cocopeat, in terms of wetting diameter and depth, as compared to other substrates, had better conditions. In contrast, the growth media containing zeolite did not perform well. The discharges of 2 and 3 liters per hour led to forming a more suitable wetting distribution pattern. For the perlite-cocopeat medium in the beds with a width of $40 \mathrm{~cm}$, a row of drip tape or a row of dripper tubes with $20 \mathrm{~cm}$ intervals between drippers could be suitable for forming the wetting distribution pattern in the whole media.

\section{References:}

1. Asadi, Z., and N. Yazdan Panah. 2015. Modified wetting distribution and reducing used water by employing super absorbent Herbozorb and Coco peat in drip irrigation. $2^{\text {th }}$ National Conference on the application of science and new technology in agriculture, natural resources and the environment. Meybod, Iran. (in Persian).

2. Iqbal, M., Ghumman, A.R., Hashmi, H.N., 2017. Study of wetting pattern under drip-emitter using sand box model and empirical equations. Pakistan Journal of Agricultural Sciences. 54: 699-709.

3. Moslehi, M., 2014. Determining water consumption and the effect of saline water on lettuce characteristics in different soilless substrates. MSc Thesis, Isfahan University of Technology. Isfahan, Iran.

4. Polat, E., Karaca, M., Demir, H., Onus, A.N., 2004. Use of natural zeolite (clinoptilolite) in agriculture. Journal of Fruit and Ornamental Plant Research. 12(1): 183-189. 